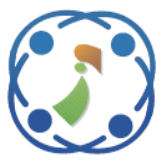

\title{
A Framework of Computational Model for Predicting the Spread of COVID-19 Pandemic in Saudi Arabia
}

\author{
Abdullah Baz $^{1 *} \quad$ Hosam Alhakami ${ }^{2} \quad$ Ebtihal Alshareef $^{2,3}$ \\ ${ }^{1}$ Department of Computer Engineering, College of Computer and Information Systems, \\ Umm Al-Qura University, Makkah, Saudi Arabia \\ ${ }^{2}$ Department of Computer Science, College of Computer and Information Systems, \\ Umm Al-Qura University, Makkah, Saudi Arabia \\ ${ }^{3}$ King Saud bin Abdulaziz for Health Science University, Saudi Arabia \\ * Corresponding author's Email: aobaz01@uqu.edu.sa
}

\begin{abstract}
The whole world is reeling under the brunt of Severe Acute Respiratory Syndrome Coronavirus 2 (SARSCoV-2 virus or COVID-19 disease) at present. Ever since the first case of this highly contagious virus was detected in Jinyintan Hospital in Wuhan, in December 2019, the disease has spread rapidly in Saudi Arabia and entire world. The current situation is extremely critical and as per the data released by WHO (the World Health Organisation), till 22 May 2020, there were 5,265,750 confirmed cases in the world. In Saudi Arabia alone there were 67,719 COVID-19 patients till 22 May, 2020 and the numbers continue to rise as more people get afflicted by this virus. Generating appropriate, knowledgeable and consistent estimates for the pandemic COVID-19 disease is an enormous challenge. Tackling this virus has become the key objective of both the government as well as the entire medical and scientific community across the world. Responding to the compelling contingency of COVID-19 pandemic, this research pursuit intends to develop a computational model that can be used to gauge the spread of Coronavirus and predict the most vulnerable regions that are likely to be affected by it. Furthermore, the framework of the model also analyzes the impact of Coronavirus on various societal factors. Once identified, these factors can be prioritized so as to device accurate and efficient countermeasures. For developing the expected model, the study has adopted the Fuzzy-AHP technique of computational modeling. Moreover, a decision making technique and severity analysis technique along with the prioritization Fuzzy-AHP approach has been employed to validate the efficacy of the suggested model. Through rigorous study of different models of COVID-19, the proposed framework provides the best model to use according to the social factors prevalent in a country. After evaluation through fuzzy AHP, the priority of proposed model is found to be the highest amongst the seven other models used for comparison. Though the present study is aimed at adding to the government's initiatives to counter the current health emergency in the Kingdom of Saudi Arabia, the proposed computational model can be an effective aid for the specialists across the world working on containment strategies to minimise the spread of Coronavirus.
\end{abstract}

Keywords: COVID-19, Infection dynamics, Computational modelling, Disease prediction.

\section{Introduction}

The world is battling with the highly infectious and fatal Severe Acute Respiratory Syndrome Coronavirus 2 (SARS-CoV-2 virus or COVID-19 disease) at present [1]. COVID-19 has unleashed a series of fatalities in the whole world, especially in the Middle-East countries [2]. Every country is combating with COVID-19 and trying to stop and mitigate the spread of virus effectively. The contagion has not only crippled the health and wellbeing of the people but also disrupted the lifestyles and occupations of millions across the world. Since most of the countries are in lockdown mode, economies across the world are also set to face extreme recession. This would further compound the misery of the people already suffering due to the 
adverse conditions imposed on them in the efforts to contain the spread of the pandemic.

Amidst this gloom, digitalization can be the much needed panacea to control and manage the spread of COVID-19 [3, 4].

Digital technology can assist the medical and the scientific fraternity in tracing, mapping and identifying the pattern of transmission of virus into humans. Several research studies have developed mathematical models to identify and understand the infection patterns of Coronavirus, its' transmission chain and the scale of virus's spread with respect to different geographical regions [5, 6]. However, most of the research that is available till now in this domain is unable to associate the impact of various factors like population birth ratio, compatibility issues in between infected and isolated people's ratio, etc. The impact of these factors also must be evaluated as they are vital referral points in preparing policies for containing the spread of the virus.

The proposed framework in the present study is an attempt to bridge the gap between the previously designed theoretical models and their actual implementation. This study, in particular, enlists the advance computational Fuzzy-AHP methodology that can be an effective mechanism for analyzing and minimizing the spread of COVID-19 in the Kingdom of Saudi Arabia. Fuzzy AHP is an extension of AHP intended to address fuzzy hierarchical things. "Fuzzy AHP" is a term used for a wide variety of methods, many of which allow a pair-wise comparison matrix to be fuzzified.

Fuzzy techniques are especially useful in estimating research inputs which might be imprecise or ambiguous. Fuzzy multiple attribute decisionmaking approaches were introduced due to ambiguities that crop up in determining the relative value of attributes and alternative performance scores with respect to attributes. Imprecision may arise from a variety of reasons: unquantifiable data, missing data, inaccessible data and limited irrationality. Ways of understanding-attribute decision-making approaches do not accommodate this varied knowledge spectrum effectively. Our research study provides a computational model of current COVID-19 virus infection dynamics to understand the spread of virus in Saudi Arabia. We have used Fuzzy-AHP for prioritizing the methodologies being employed to control the spread of COVID-19 and other pandemics. In this context, Fuzzy-AHP is the most conversant approach for prioritizing the various methodologies and ranking them as per their weights obtained through step-wise calculations. In addition, the model also describes the impact on society by applying the decision making process.
The defining aspects of the proposed computational model are as follows:

- The severity, management and mitigation of risks involved resulted through the society factors are considered in this framework. This framework is unique as it is premised on the impact of the COVID-19 disease on the society and pertains to specific social indices that are being affected due to the virus. Moreover, the model is a collation of the three integrated dimensions that include: Mapping the severity, management, and mitigation strategies to contain the virus.

- Seven similar models were taken to validate the proposed model through the same dataset.

- A case study of Saudi Arabia has been taken for evaluating the results for all the eight models.

- Application of the proposed framework will help the practitioners to mitigate the spread of the disease by suggesting the possible countermeasures.

Saudi Arabia is a country with stable economy empowered with fully digitalized and developed healthcare infrastructure. However, the present day COVID-19 health emergency calls for prompt and effective containment strategies to prevent any further loss of lives as well as stem economic loss to the country [7]. The proposed framework evaluates the impact of virus on economy and predicts the future situation of economy on the basis of current spread.

Rest of the paper is structured as follows: Section two describes the literature regarding previously proposed models for assessing the impact of COVID19 and other pandemics. Third section describes the need and importance of the proposed work. Section four refers to the description of proposed framework. Section five presents the effectiveness of the proposed model and compares it with the other seven models. The sixth section concludes the study.

\section{Literature review}

Mathematical modelling of COVID-19 spread dynamics has been undertaken by several researchers. However, very few research efforts have focused on developing a computational model to analyse the spread and impact of Novel Coronavirus. Thus, our study aspires to design a computational model that systematically traces the reach of the pandemic, its' magnitude and impact on different locales along with standardized mitigation mechanisms that can be used by the experts working on countermeasures to control Coronavirus. Towards this intent, the authors have undertaken an in-depth perusal of the existing literature available in this domain. Moreover, the 
industrious scrutiny of the present research repository helped us in developing a framework that would offer highly accurate predictions in a seamless manner for prompt and reliable results. Further, a wrong or slightly misconfigured modelling technique can produce opposite and wrong predictions and model. This type of situation misleads a country or governing body. For mitigating this type of situation in KSA, authors examine and analyze various relevant research articles and topics that help the contributors into building this research idea. The references that were integral to our research objective are listed below:

A. Rachah et al. published a mathematical modelling study on Ebola virus in West African region. The authors simulated the results evaluated through a typical mathematical model technique. The researchers explained the Ebola outbreak and used the mathematical model to map the spread of virus in the West African region and simulated these results through an appropriate methodology [2]. The model in this work inspired our research commitment in developing a computational model that could map as well as predict the spread of COVID-19. Further this research did not provided any kind of guidelines to follow which can be followed to stay uninfected from Ebola Virus.

T. M. Chen et al. proposed a study on Corona virus spread and analyzed the virus in a phase-based pattern. The study also proposed a mathematical modelling approach called Bats-Hosts-ReservoirPeople Transmission Network Model that simulated the transmission of Coronavirus into humans [3]. The study traced the spread from seafood market of China and analysed its effect on the people and the locality in general. The authors used next generation matrix approach to identify the reproduction number (R0) of the virus. We found this study to be a useful reference in determining the possible source and the pattern of transmission of Coronavirus. However, the cited study does not take any social factor into account for evaluating the impact of COVID-19.

Y. Li et al. published an article with effective and exhaustive modelling and prediction of novel COVID-19 virus in China. The paper systematically analyzes the situation of COVID-19 virus in China and then uses a mathematical modelling approach for understanding the outbreak. The paper also predicts about the possible situation of virus and proposes few countermeasures for mitigating the outbreak of the pandemic. This study uses a Six Chamber Dynamic Model and a time series model to establish a time variation in the original data. The paper enlisted the SEIQDR-based method and TS Model-based method for evaluating the Virus's spread and predicting the possible outbreak of the pandemic [4]. Based on the results drawn from the analysis, the authors proposed measures for containing the current situation of COVID-19 virus. This study was essentially premised on the Coronavirus data in China only. In the same league, we were also motivated to develop a computerized system for predicting the spread of all communicable diseases (including COVID-19) in Saudi Arabia.

Adam J Kucharski et al. provided a study on transmission of Coronavirus from human to human. The study analyzed the spread of infection in Wuhan from December 2019 to February 2020. Authors obtained effective results and recommended countermeasures that could be undertaken by the Chinese's government. The paper used a Stochastic transmission model associating it with Corona case vectors that provides an effective analysis mechanism to the authors. The study concluded that there are $50 \%$ chances of spread of Coronavirus in Wuhan, China [5]. However, this model also did not consider any of the social factors and attributes in evaluating the impact of COVID-19. This study was an important reference point for our research endeavour, especially in selecting the relevant data resources from various time periods to clearly understand the spread of the virus. The paper has effective contribution in modelling and understanding the spread of COVID-19 virus spread.

L. Sheryl et al. provided a transmission model to control COVID-19 in Australia. The paper used an agent-based model for modelling the fine-grained computational simulation of pandemic of COVID-19 [6]. The study used an age fraction model to estimate the results of death and condition of COVID-19 virus in Australia. Nevertheless, there were no guidelines in this work which could provide solutions for fewer infections in the world.

For understanding the impact of virus on humans, M. Erraguntla et al. have discussed about the various factors that affect the transmission of virus among humans in their study. The paper cites several factors like environmental conditions, vector dynamics, social and cultural behaviour that are responsible for accelerating the rate of transmission of the virus and infecting the community [7]. This study, in particular, became the base for our research analysis to focus on core social factors that could be abetting the transmission of Coronavirus in Saudi Arabia.

In the context of computational modeling, we examined the established literature to foreground our empirical investigations. The studies that were referred to are:

S. Marino et al. provided an outcome on Mycobacterium Tuberculosis-Specific T Cells as a 
Biomarker through a computational modelling approach [8]. The results of this study verified the scope and potential of computational modelling in dealing with the diseases effectively.

I.G. Arpin et al. presented a modelling and estimation paper discussing about the cardiovascular surgery burden in Saudi Arabia. The paper shows about the future growth as well as categorizes the burden of surgeries in Saudi Arabian healthcare organizations [9]. In the context of our project, the quoted study can be construed as the best practice for modeling. Project authors find this study relatively beneficial as a best experience in modelling perspective for Saudi Arabia.

Sultanah Alshammari et al. presented a computational model for assessing the risk of mass gathering epidemics. The paper effectively presents the situation of high mass gathering as Olympic Games, FIFA world cup, Hajj, etc. The presented paper selects Hajj as a case and use Data-Driven computational model to assess the risk of any type of epidemic in huge mass gathering. The paper proposed a Stochastic SEIR (Susceptible-Exposed-Infected-Recovered) agentbased model for modeling the epidemic clearly and effectively [10]. This study also contributes as a previous experience in relevant work of proposed project and helps the authors to understand the situation and challenges of proposed work.

M. Quasim et al. presented approximate growth in COVID-19 virus through a mathematical modelling approach. The paper uses a Successive Approximation Method to evaluate the pandemic situation in worldwide perspective [11]. The paper tries to present an effective evaluation but has many shortcomings and flaws. This proposed project uses this study as an informative paper and tries to solve the challenges rises in this study.

A study undertaken by Franz-Josef Schmitt examined the situation of disease after the implementation of prevention mechanisms. This paper uses a mathematical modelling approach to quantitatively measure the effect of social distancing and other applied prevention methodologies. The paper provides a detailed scrutiny of the possible effects of various social distancing models that are being instituted in Germany and USA. The paper discusses about the routes of virus's spread as well as the other possible routes [12]. This study helped us to assess the countermeasures and their aftereffects on the various social factors that we have considered in our research analysis.

C. Hou et al. presented a paper that discusses about the quarantine effect in China by using SEIR model. The paper discusses about the isolation prevention methodology and finds that such mechanisms help in reducing the spread of COVID19 [13].

Z. Cakir et al. presented a mathematical modeling of the novel COVID-19 virus on the $\mathrm{H}$ number of individuals. The paper works on a theory that says that the $\mathrm{H}$ number of individuals who are infected by the virus is propositional to the multiplication of the number of those who have been infected by the disease and those who have not [14]. The study concludes by predicting wide scale spread of Coronavirus in China due to low prevention mechanisms and high infection spread ratio. This study helped us in identifying the time-dependent changes that affect the modeling.

\section{Need and importance}

Authors of the article found that there are various research studies available on mathematical modelling of COVID-19 spread dynamics. However, very few research studies have been on computational modelling for the spread of COVID-19 [8-15]. As experts around the world are researching on preventive mechanisms, modelling the spread of COVID-19 will provide a systematic view for introducing accurate countermeasures. A wrong or slightly misconfigured modelling technique can produce opposite and wrong predictions, framework and model. Hence before conceptualising the suggested framework, the authors of the present study examined and analyzed various relevant research endeavours available in this domain.

After a thorough perusal of the nodal aspects of the abovementioned research pursuits, we concluded that there is yet no simulation study available on the analysis of COVID-19 virus and in KSA. An effective modelling study would provide the strategists with the necessary data required to formulate containment policies for controlling the virus in the severely affected regions of Saudi Arabia. Moreover, the proposed computational model can also be a template for tracing and predicting the spread of other epidemics in Saudi Arabia. Depicting the correct infection dynamics through an appropriate methodology would further enhance the war against the virus. A correct and effective approach provides the potent weapon against a virus spread. 67,500 cases of COVID-19 were recorded till May 22, 2020 in Saudi Arabia. $10 \%$ of these cases are the test cases [15]. However, according to a report, this figure may rise to 2,000,000, if the prescriptive actions are not taken [16]. Thus, the need for an appropriate model that evaluates the possible spread ratio as well as 


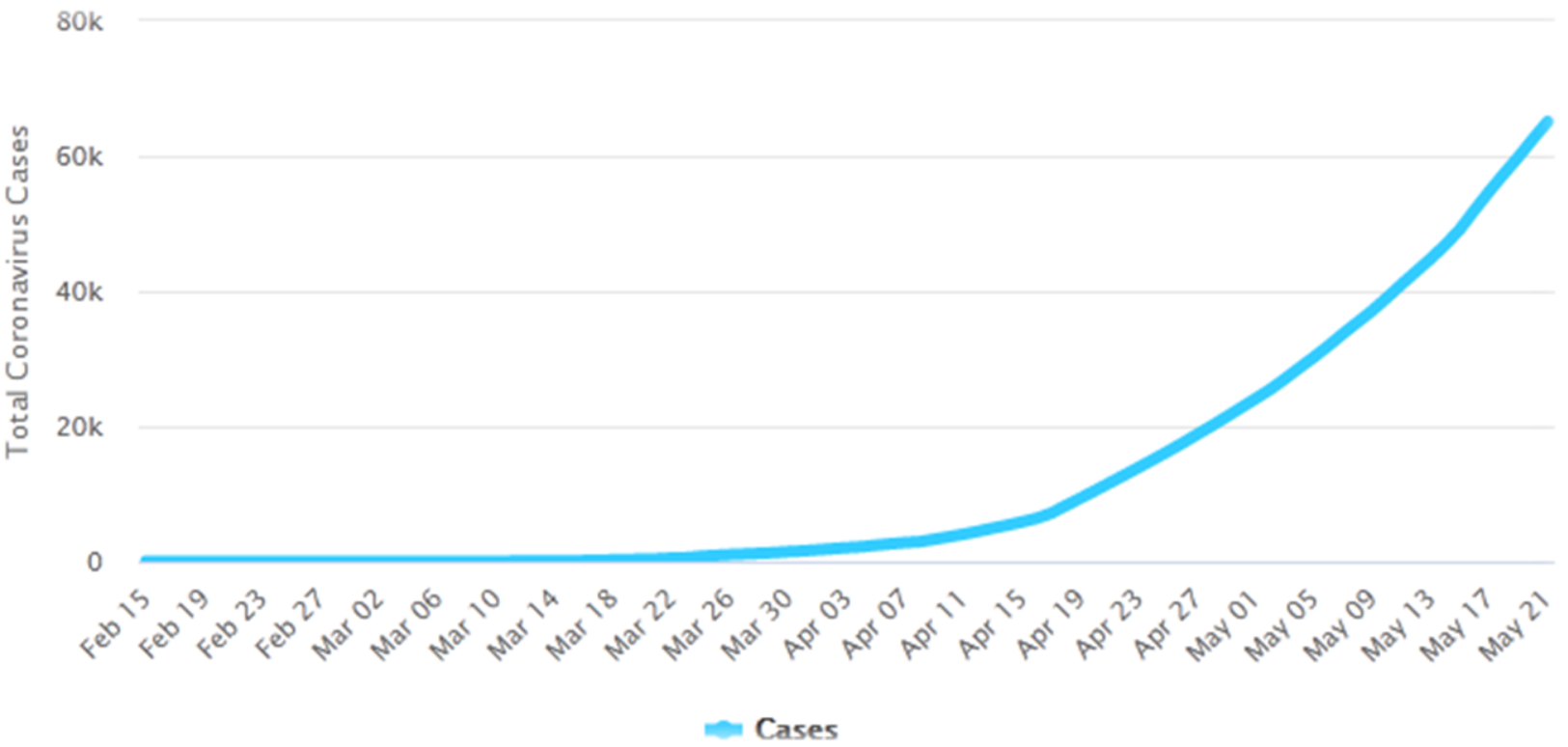

Figure. 1 Total cases in Saudi Arabia

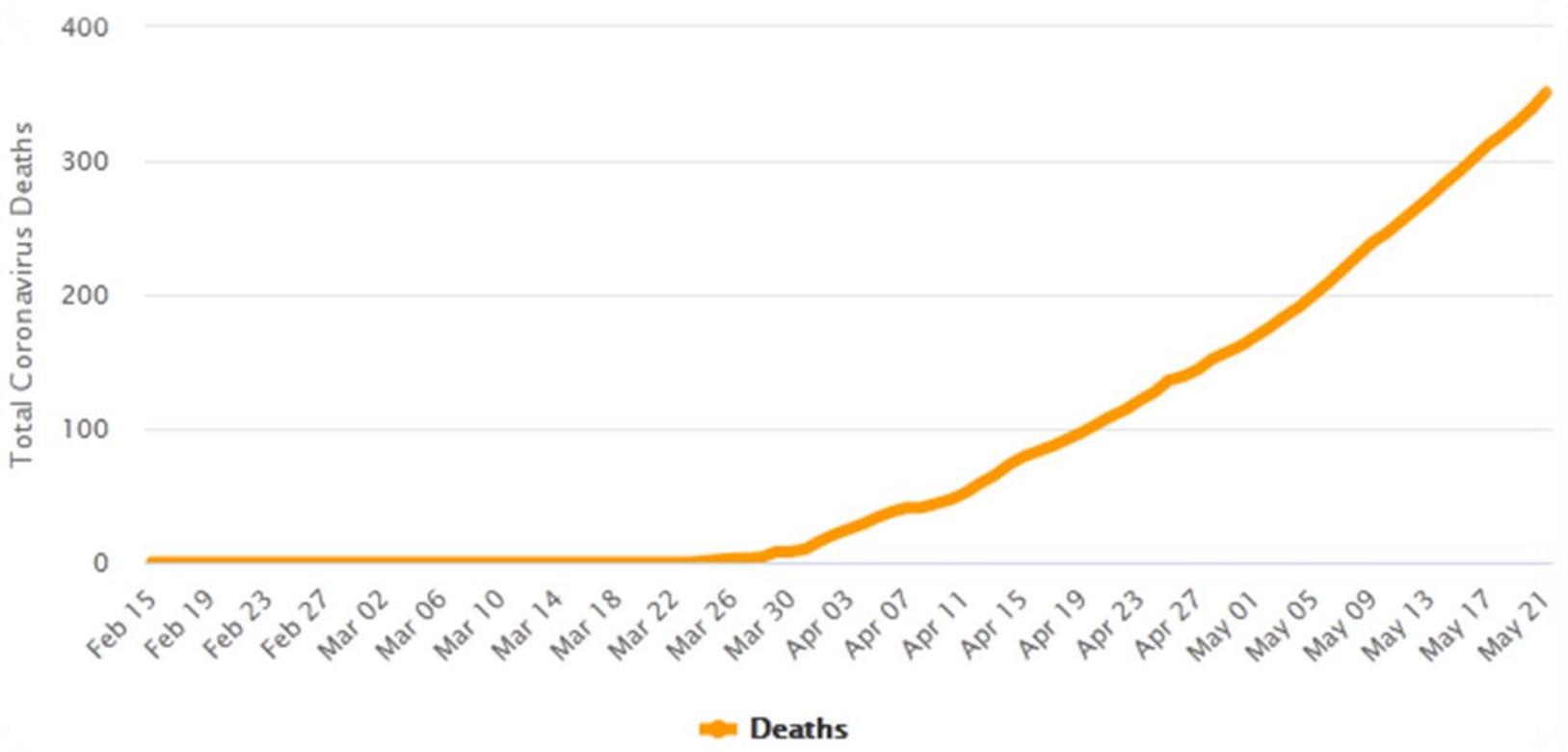

Figure. 2 Total deaths in Saudi Arabia

proposes various impact factors and their respective countermeasures cannot be overstated. The current statistics are shown in Fig. 1, 2 and 3 [15].

Fig. 1 and 2 show rapid and alarming increase in the number of cases as well as the number of deaths. Unfortunately, difference between new cases and new recoveries is very large, as evident in Fig. 3. By adapting the population growth models and the data from the world's Coronavirus statistics, Eindhoven statisticians/data scientists have measured the estimated number of new COVID-19 virus infections and losses for the immediate future.

The statisticians are trying to make the most reliable daily estimation, one to three days ahead and also predict the maximum number of confirmed infections for twelve countries which are: China, South Korea, the United States, Canada, Iran, Italy, France, the United Kingdom, Spain, Belgium, Switzerland, Austria, Germany and the Netherlands. Furthermore, the data scientists are constantly refining their models by using the regularly updated data to make their predictions more accurate.

A dangerous trend of COVID-19 is that this virus contains a large spread of symptoms that affect people in different ways. Many infected people are symptomless, others have only mild symptoms, some get very sick, and some develop a complete illness that threatens their lives. Thus, this unpredictability 


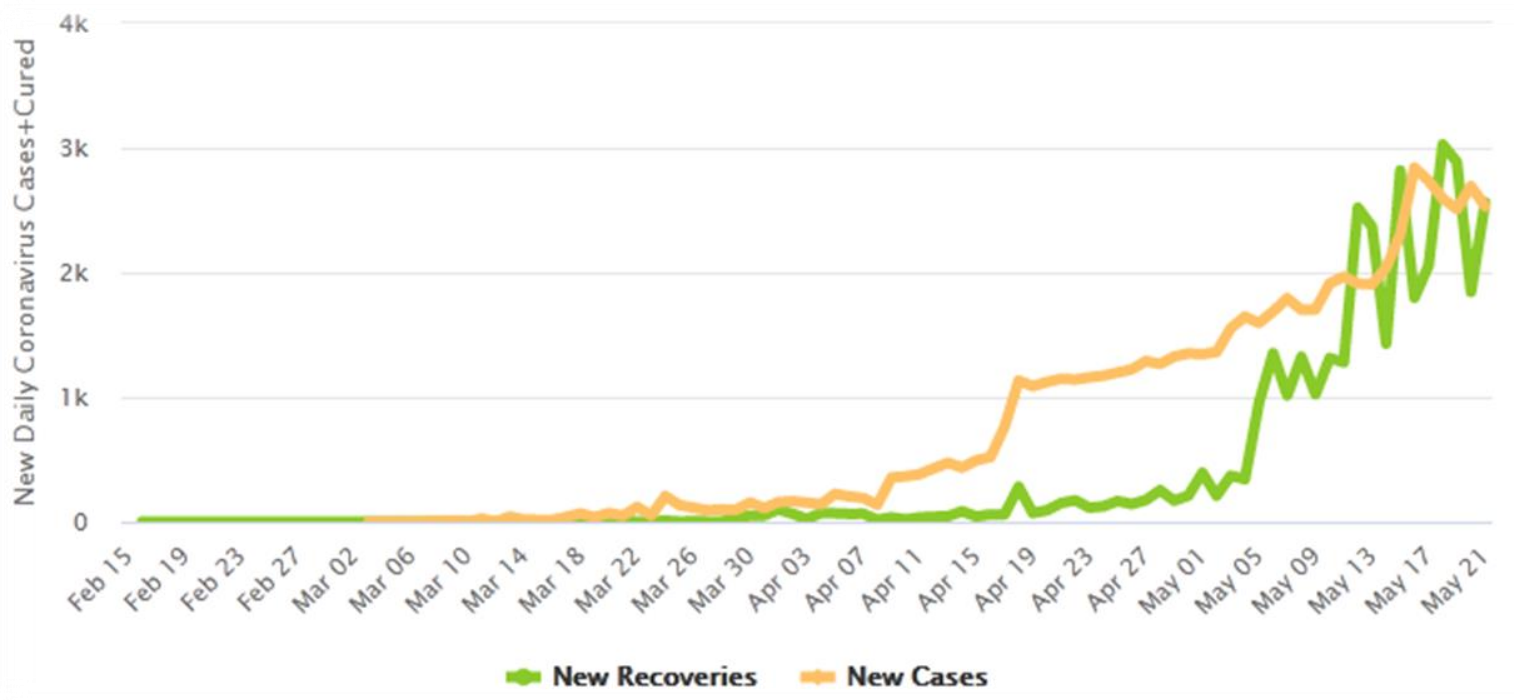

Figure. 3 Difference between new cases and new recoveries in Saudi Arabia

also inhibits precision in analyzing the data. Our research is premised on certain observations cited by the medical specialists as part of preventive steps to contain the infection. These observations are:

- Elderly people and the children (0-5 years) are more susceptible to Coronavirus infection.

- People with history of diabetes are more likely to contact the infection.

- Those with weak immunity are also highly vulnerable target groups.

- The virus is transmitted by human to-human interaction, particularly through droplets. Since the scale of transmission is extremely rapid, the dangers of community spread and massive fatalities cannot be ruled out.

These conclusions were taken into consideration while developing the proposed framework. Although many practitioners have dwelt upon the problems and infection dynamics worldwide and in KSA, there is still no common or standardized mechanism for tracing COVID-19 outbreak. Thus, our study is an initiative to propose a standardised framework which can help in devising more effective countermeasures to contain COVID-19.

\section{Proposed framework}

The present COVID-19 scenario calls for the developers to focus on different computing techniques for providing a systematic management and mitigation process for future. This will help in developing guidelines for fighting the pandemic in Saudi Arabia. The practitioners are trying to design a mechanism to predict the spread of infection. But, in today's scenario, it is very difficult to predict the spread of COVID-19 without any standard system. At the same time it is also very important to prevent the spread of infection at ground level. The key question in this regard is how to predict the spread of infection with better mechanism to face the challenges related to COVID-19 issues.

Hence, a common framework for predicting spread of infection is in demand. By leveraging its unique expertise, this article offers a framework for prediction of pandemic disease like COVID-19. The idea of framework is prepared for unified virus computational modelling and prediction but the study takes COVID-19 as a testing case due to its huge effect on the lifestyles and the wellbeing of the people, more so in the context of Saudi Arabia. The results elicited will be highly effective in mitigating the affects of COVID-19 on societal, economical and technical indices. A descriptive analysis of these phases is explained and described in figure 4 .

After analysing the goals thoroughly, there is need of a prescriptive framework. To achieve the specific objectives there is always a pathway needed. The proposed framework is also the pathway to the prescriptive guidelines to be generated at the end of this project. The framework is categorized into three basic phases called: Monitoring, Mitigating and Managing.

Monitoring phase: This phase maps the steps to follow for developing the Computational model. Monitoring phase includes two steps and these steps are described in the following headings:

- Acquire current infection ratio and vector: This step includes the initial steps to start the 


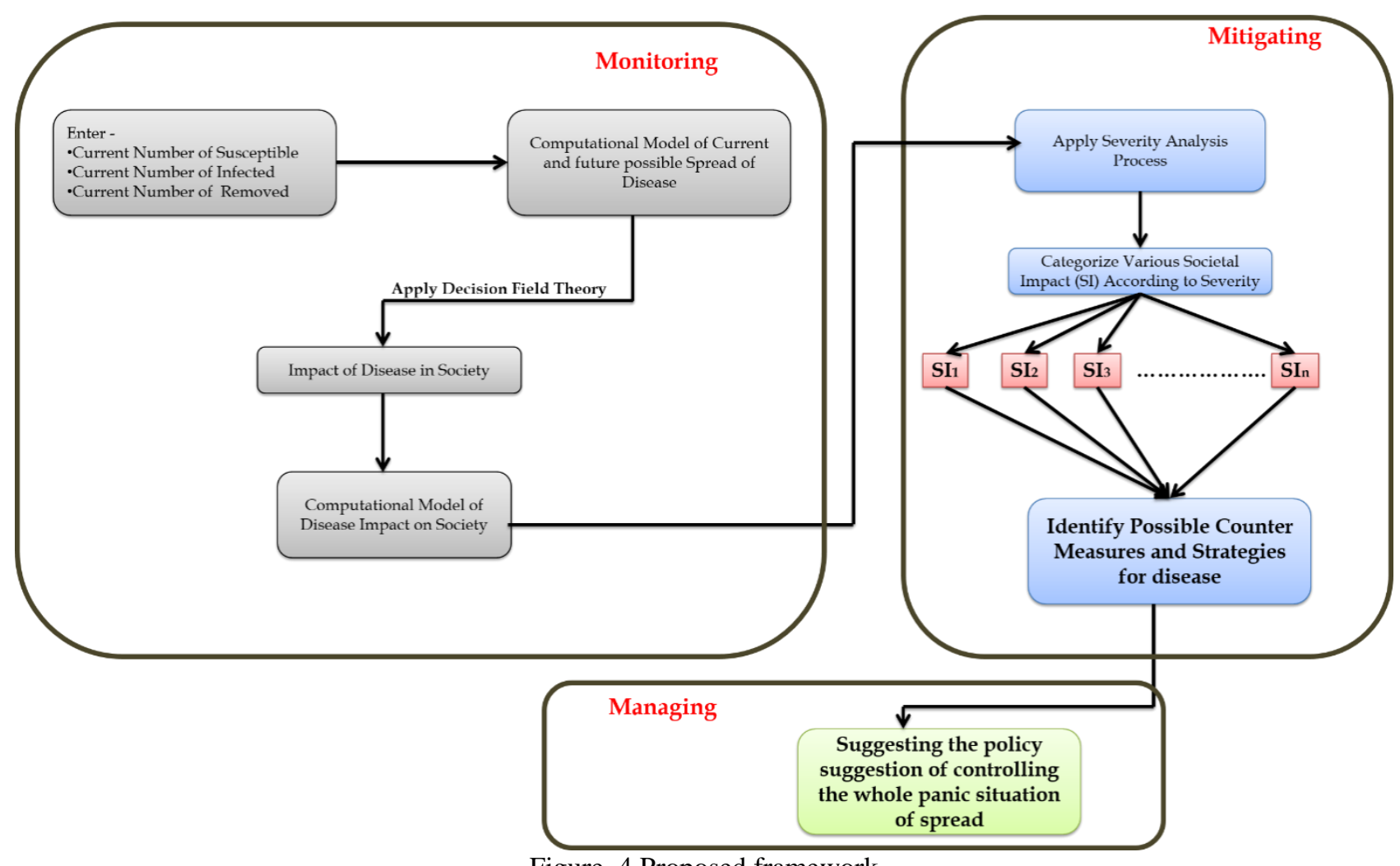

Figure. 4 Proposed framework

proposed framework. In this step, we acquire the available current infection vectors under three segregations: (i) number of susceptible, (ii) number of infected and (iii) number of removed (as death or recovered). After eliciting the stated data, the framework starts the process for the second step.

\section{- Conceptual/mathematical/computational}

model of spread: In this step, the model prepares a computational approach of spread ratio by using the theoretical/ mathematical framework for generating computational model. The technique and tools that are going to be used in this phase are automatic like MATLAB and other computational modelling approaches. Converting the current infection ratio into spread model provides a clear understanding of the scenario and helps the experts. The difference between other computational models and this model is that it first identifies and categorizes the different factors of this pandemic, and then prioritizes them accordingly. This prioritization procedure has been considered in designing the computational model for predicting the possible spread of COVID-19 pandemic.

- Computational model of impact of disease on society: This step includes the modelling of calculated results on the step of analyzing the impact of disease on society. The proposed framework computationally models the various impacts for providing a clear view on relevant factors.

Mitigating phase: It is the second phase in which the framework uses a decision making theory of computational modelling and the categorized data of spread in computational modelling form. This phase also comes under the monitoring phase. The steps that are taken in this phase are following:

- Identify the impact of disease on society: This step involves the decision making theory approach of computational modelling. The framework analyzes the reaction of various factors according to the computational model of virus spread through the decision making theory technique. This step identifies various categories of fields like financial, social and geographical impact of the disease. The approaches used in this phase would involve Fuzzy AHP TOPSIS, Hesitant Fuzzy AHP, etc.

- Apply severity analysis process on societal impact: This process involves the severity analysis technique that calculates the severity of affected factors and assigns them their calculated priority. The factors' identification is done at the first level and they are categorized in this phase according to their severity levels. 
- Categorization of various societal impact factors according to severity: In this step, the framework categorizes different factors according to their level of severity. This step considers the various societal factors and their importance according to the previous two levels that is impact and severity analysis.

- Detect possible countermeasure and strategy: In this step, through the previous best practices and experiences, the framework identifies the appropriate countermeasures for every affected factor according to the severity level.

Managing phase: The managing phase uses severity analysis techniques for finding the most and least savvy factor from impact analysis. The following steps are undertaken for this process:

- Suggesting the policy for controlling the whole panic situation of spread: This step includes policies and suggestions that would for controlling the spread of the virus.

As per the forewarnings issued by the WHO, Corona crisis is not likely to dissipate for another two to six months. Moreover, the economic fallout triggered by COVID-19 debacle is predicted to be even worse. In the absence of any defined course of medication or a vaccine to prevent the contagion's spread, the best recourse is to adapt the three $M$ strategy of Monitoring, Mitigating and Managing. Against this backdrop, the framework structured by us is a cohesive and systematic approach that can be adapted to trace the potentially susceptible targets of the pandemic. Furthermore, the gravity of the crisis is such that it requires remedial mechanisms that are prompt, cost-effective and result-oriented. A standardised framework, as explicated above, integrates these prerequisites.

Further, it is known that several mathematical and theoretical frameworks have already been developed. Hence effectiveness of our proposed framework needs to be corroborated. For this reason, we have taken seven popular mathematical and theoretical frameworks proposed by different researchers and academicians and compared our framework with theirs. Next section discusses the effectiveness of the proposed approach.

\section{Effectiveness of the proposed model}

For establishing the efficacy and accuracy of our computational model, we have compared the Proposed Framework/ Model (M8) with other seven frameworks/ models developed in previous research initiatives. These seven distinctive models are: Reservoir People Transmission Network Model (M1)
[2], Time Series Model (M2) [9], Spreading Rate of the Disease Model (M3) [10], Susceptible Infected Recovered Model (M4) [11], Dynamic Model (M5) [13], Multi Modelling Approach Model (M6) [14], Susceptible Exposed Infectious Recovered Model (M7) [15].

For evaluating the effectiveness of the proposed model, this article has taken the Fuzzy AHP method [17-20]. Fuzzy AHP method is used as a tool for evaluating the effectiveness of a criterion from a set of criteria and is apt for providing precise decisions [21-23]. Authors have used this tool to assess the most prioritized prediction model for the pandemic. This type of classification and decision provides a novel and valuable idea to the future researchers. In order to conduct the Fuzzy-AHP methodology, the authors have used this technique previously [24-26] and collected data from different experts. The responses were collected and then compiled by using fuzzy AHP membership functions.

Based on the membership functions, we selected the most prioritized prediction model for the pandemic. With the help of the equations [27-30], the constructed and aggregated fuzzy comparison matrix was prepared. Table 1 shows the fuzzy pair-wise comparison matrix in the form of triangular fuzzy numbers [31-33]. To evaluate the defuzzify values and Consistency Ratio (CR) values of the matrix, the authors adopted [34-36] processes. For defuzzification process, this paper used $\alpha$ cut method [37-39]. Table 2 shows the defuzzified pair-wise comparison matrix. Final weights of the group are also shown in the Table 2. Finally, the overall weights and priority of the models have been shown in Fig. 4.

Different methodologies have been used in different pandemics. This empirical investigation specifically used Fuzzy AHP for prioritizing the methodologies and concluded that the highest weighted methodology was that of the Computational Model proposed in the present study. According to the quantitative assessment in Table 1, Table 2 and Fig. 4, the proposed model obtained the highest priority with a weight of 0.25650 , and the CR value of 0.0333 . In addition, prioritization of the models in the descending order is: M8>M6>M5 $>$ M4 $>$ M3 $>$ M7 $>$ M1. Proposed Model (M8) has obtained the highest weight (0.25650), Model 6 (M6) obtained the second highest rank and weight (0.17290), whereas the Model 1 (M1) obtained the lowest rank and weights (0.07330). By the obtained ranks and weights, authors assigned the ranks to the models being used in minimizing the COVID-19 spread. Thus, the conclusive results further iterate that M8 will be the best model that can be applied for minimizing the spread of COVID-19 
Table 1. Aggregated fuzzy comparison matrix of models

\begin{tabular}{|c|c|c|c|c|c|c|c|c|}
\hline & M1 & M2 & M3 & M4 & M5 & M6 & M7 & M8 \\
\hline $\begin{array}{c}\text { Reservoir } \\
\text { People } \\
\text { Transmission } \\
\text { Network } \\
\text { Model 1 (M1) }\end{array}$ & $\begin{array}{l}1.00000, \\
1.00000, \\
1.00000\end{array}$ & $\begin{array}{l}1.00000, \\
1.51570, \\
1.93310\end{array}$ & $\begin{array}{c}0.48960 \\
0.63720 \\
1.00000\end{array}$ & $\begin{array}{c}0.41520 \\
0.57430 \\
1.00000\end{array}$ & $\begin{array}{l}0.22150, \\
0.28710, \\
0.41520\end{array}$ & $\begin{array}{l}0.31460, \\
0.46100, \\
0.87050\end{array}$ & $\begin{array}{l}0.65750, \\
1.16530, \\
1.68830\end{array}$ & $\begin{array}{l}0.24440, \\
0.32380, \\
0.48010\end{array}$ \\
\hline $\begin{array}{c}\text { Time Series } \\
\text { Model } 2 \text { (M2) }\end{array}$ & - & $\begin{array}{l}1.00000, \\
1.00000, \\
1.00000\end{array}$ & $\begin{array}{l}0.57430 \\
0.66570 \\
0.80220\end{array}$ & $\begin{array}{c}0.30390 \\
0.39360 \\
0.56610\end{array}$ & $\begin{array}{l}0.26790, \\
0.35210, \\
0.51760\end{array}$ & $\begin{array}{l}0.16630, \\
0.19690, \\
0.25310\end{array}$ & $\begin{array}{l}0.39300, \\
0.57430, \\
1.05640\end{array}$ & $\begin{array}{l}0.16920, \\
0.20760, \\
0.27590\end{array}$ \\
\hline $\begin{array}{c}\text { Spreading } \\
\text { Rate of the } \\
\text { Disease Model } \\
3 \text { (M3) }\end{array}$ & - & - & $\begin{array}{l}1.00000 \\
1.00000 \\
1.00000\end{array}$ & $\begin{array}{l}1.00000, \\
1.31950, \\
1.55180\end{array}$ & $\begin{array}{l}0.30090, \\
0.43520, \\
0.80270\end{array}$ & $\begin{array}{l}0.80270, \\
0.87050, \\
1.00000\end{array}$ & $\begin{array}{l}1.26190, \\
1.82500, \\
2.43340\end{array}$ & $\begin{array}{l}0.17280, \\
0.20910, \\
0.26480\end{array}$ \\
\hline $\begin{array}{l}\text { Susceptible } \\
\text { Infected } \\
\text { Recovered } \\
\text { Model } 4 \text { (M4) }\end{array}$ & - & - & - & $\begin{array}{l}1.00000 \\
1.00000 \\
1.00000\end{array}$ & $\begin{array}{c}0.53860 \\
0.91430 \\
1.58360\end{array}$ & $\begin{array}{l}0.60830, \\
1.05920, \\
1.68290\end{array}$ & $\begin{array}{l}0.75030, \\
1.34650, \\
1.96110\end{array}$ & $\begin{array}{l}0.67900, \\
0.74890, \\
0.87050\end{array}$ \\
\hline $\begin{array}{c}\text { Dynamic } \\
\text { Model } 5 \text { (M5) }\end{array}$ & - & - & - & - & $\begin{array}{l}1.00000 \\
1.00000 \\
1.00000\end{array}$ & $\begin{array}{l}0.41520, \\
0.63720, \\
1.17910\end{array}$ & $\begin{array}{l}0.94650, \\
1.10950, \\
1.24570\end{array}$ & $\begin{array}{l}0.25000, \\
0.33000, \\
0.50000\end{array}$ \\
\hline $\begin{array}{c}\text { Multi } \\
\text { Modelling } \\
\text { Approach } \\
\text { Model } 6 \text { (M6) }\end{array}$ & - & - & - & - & - & $\begin{array}{l}1.00000, \\
1.00000, \\
1.00000\end{array}$ & $\begin{array}{l}1.88810, \\
2.55080, \\
3.16970\end{array}$ & $\begin{array}{l}0.80270, \\
1.03520, \\
1.31600\end{array}$ \\
\hline $\begin{array}{l}\text { Susceptible } \\
\text { Exposed } \\
\text { Infectious } \\
\text { Recovered } \\
\text { Model } 7 \text { (M7) }\end{array}$ & - & - & - & - & - & - & $\begin{array}{l}1.00000, \\
1.00000, \\
1.00000\end{array}$ & $\begin{array}{l}0.21360, \\
0.25750, \\
0.31950\end{array}$ \\
\hline $\begin{array}{c}\text { Proposed } \\
\text { Model } 8 \text { (M8) }\end{array}$ & - & - & - & - & - & - & - & $\begin{array}{l}1.00000, \\
1.00000, \\
1.00000\end{array}$ \\
\hline
\end{tabular}

pandemic. A fully tested and validated computational model as the one proposed in our study would be a significant contributor at the time of any health emergency in a country.

\section{Conclusion}

Computational modelling is an effective tool which helps to estimate key transmission parameters through total efforts. The model also includes automated tools, decision analysis, Fuzzy-AHP for computation and dynamic analysis, which play an important role for controlling pandemics. The framework developed by us is based on the previously designed Coronavirus models and incorporates Fuzzy-AHP computational simulations and sensitivity analysis concept. Fuzzy-AHP tool is used for prioritizing the available methods to control the spread of COVID-19. This framework has three phases including monitoring, mitigating and managing COVID-19 disease. Furthermore, the proposed approach offers integration of potential approaches that can provide more focus to healthcare services and methods that would efficiently and quickly reduce the spread of COVID-19. The project has the following practical/ scientific utilities:

- The results from the above computation shows that the proposed approach is better in comparison to other models if societal impact is considered as an important factor.

- The proposed project provides a systematic framework for predicting the infection dynamics, and the impact of Novel Coronavirus on the social and economic factors in KSA. 
Table 2. Defuzzified Values and Overall Weight of Models

\begin{tabular}{|c|c|c|c|c|c|c|c|c|c|}
\hline Models & M1 & M2 & M3 & M4 & M5 & M6 & M7 & M8 & $\begin{array}{c}\text { Weight } \\
\text { s }\end{array}$ \\
\hline $\begin{array}{c}\text { Reservoir } \\
\text { People } \\
\text { Transmissio } \\
\text { n Network } \\
\text { Model 1 } \\
\text { (M1) }\end{array}$ & $\begin{array}{c}1.0000 \\
0\end{array}$ & $\begin{array}{c}1.4912 \\
0\end{array}$ & $\begin{array}{c}0.6910 \\
0\end{array}$ & $\begin{array}{c}0.6410 \\
0\end{array}$ & $\begin{array}{c}0.3027 \\
0\end{array}$ & 0.52680 & $\begin{array}{c}1.1691 \\
0\end{array}$ & $\begin{array}{c}0.3430 \\
0\end{array}$ & 0.07330 \\
\hline $\begin{array}{c}\text { Time Series } \\
\text { Model } 2 \\
\text { (M2) }\end{array}$ & $\begin{array}{c}0.6706 \\
0\end{array}$ & $\begin{array}{c}1.0000 \\
0\end{array}$ & $\begin{array}{c}0.6770 \\
0\end{array}$ & $\begin{array}{c}0.4143 \\
0\end{array}$ & $\begin{array}{c}0.3724 \\
0\end{array}$ & 0.20330 & $\begin{array}{c}0.6495 \\
0\end{array}$ & $\begin{array}{c}0.2151 \\
0\end{array}$ & 0.04970 \\
\hline $\begin{array}{l}\text { Spreading } \\
\text { Rate of the } \\
\text { Disease } \\
\text { Model } 3 \\
\text { (M3) }\end{array}$ & $\begin{array}{c}1.4470 \\
0\end{array}$ & $\begin{array}{c}1.4771 \\
0\end{array}$ & $\begin{array}{c}1.0000 \\
0\end{array}$ & $\begin{array}{c}1.2977 \\
0\end{array}$ & $\begin{array}{c}0.4935 \\
0\end{array}$ & 0.85200 & $\begin{array}{c}1.8364 \\
0\end{array}$ & $\begin{array}{c}0.2140 \\
0\end{array}$ & 0.10310 \\
\hline $\begin{array}{l}\text { Susceptible } \\
\text { Infected } \\
\text { Recovered } \\
\text { Model } 4 \\
\text { (M4) }\end{array}$ & $\begin{array}{c}1.5600 \\
0\end{array}$ & $\begin{array}{c}2.4137 \\
0\end{array}$ & $\begin{array}{c}0.7706 \\
0\end{array}$ & $\begin{array}{c}1.0000 \\
0\end{array}$ & $\begin{array}{c}0.9636 \\
0\end{array}$ & 1.10240 & $\begin{array}{c}1.3511 \\
0\end{array}$ & $\begin{array}{c}0.7319 \\
0\end{array}$ & 0.12710 \\
\hline $\begin{array}{l}\text { Dynamic } \\
\text { Model } 5 \\
\text { (M5) }\end{array}$ & $\begin{array}{c}3.3036 \\
0\end{array}$ & $\begin{array}{c}2.6853 \\
0\end{array}$ & $\begin{array}{c}2.0263 \\
0\end{array}$ & $\begin{array}{c}1.0378 \\
0\end{array}$ & $\begin{array}{c}1.0000 \\
0\end{array}$ & 0.71720 & $\begin{array}{c}1.1028 \\
0\end{array}$ & $\begin{array}{c}0.4350 \\
0\end{array}$ & 0.14140 \\
\hline $\begin{array}{c}\text { Multi } \\
\text { Modelling } \\
\text { Approach } \\
\text { Model } 6 \\
\text { (M6) }\end{array}$ & $\begin{array}{c}1.8982 \\
0\end{array}$ & $\begin{array}{c}4.9188 \\
0\end{array}$ & $\begin{array}{c}1.1737 \\
0\end{array}$ & $\begin{array}{c}0.9071 \\
0\end{array}$ & $\begin{array}{c}1.3943 \\
0\end{array}$ & 1.00000 & $\begin{array}{c}2.3852 \\
0\end{array}$ & $\begin{array}{c}1.0473 \\
0\end{array}$ & 0.17290 \\
\hline $\begin{array}{l}\text { Susceptible } \\
\text { Exposed } \\
\text { Infectious } \\
\text { Recovered } \\
\text { Model } 7 \\
\text { (M7) }\end{array}$ & $\begin{array}{c}0.8554 \\
0\end{array}$ & $\begin{array}{c}1.5397 \\
0\end{array}$ & $\begin{array}{c}0.5445 \\
0\end{array}$ & $\begin{array}{c}0.7401 \\
0\end{array}$ & $\begin{array}{c}0.9067 \\
9\end{array}$ & $\begin{array}{c}0.41925 \\
0\end{array}$ & $\begin{array}{c}1.0000 \\
0\end{array}$ & $\begin{array}{c}0.2621 \\
0\end{array}$ & 0.07600 \\
\hline $\begin{array}{c}\text { Proposed } \\
\text { Model } 8 \\
(\mathrm{M} 8)\end{array}$ & $\begin{array}{c}2.9154 \\
0\end{array}$ & $\begin{array}{c}4.6490 \\
0\end{array}$ & $\begin{array}{c}4.6729 \\
0\end{array}$ & $\begin{array}{c}1.3663 \\
1\end{array}$ & $\begin{array}{c}2.2989 \\
0\end{array}$ & 0.95484 & $\begin{array}{c}3.8153 \\
0\end{array}$ & $\begin{array}{c}1.0000 \\
0\end{array}$ & 0.25650 \\
\hline
\end{tabular}

- The proposed study may help Saudi Arabian healthcare organizations in raising their revenue by using the results of the proposed work.

- Had the countries established effective preventive mechanisms and wherewithal promptly, the damage unleashed by COVID-19 would have been considerably less. Thus, the model developed in the present study would help in timely predictions, thereby lessening the impact of COVID-19 in future through prompt remedial interventions.

- The study also enlists suggestions for managing the impact of COVID-19 in KSA.

\section{Conflicts of Interest}

The authors declare no conflict of interest. 
0.3

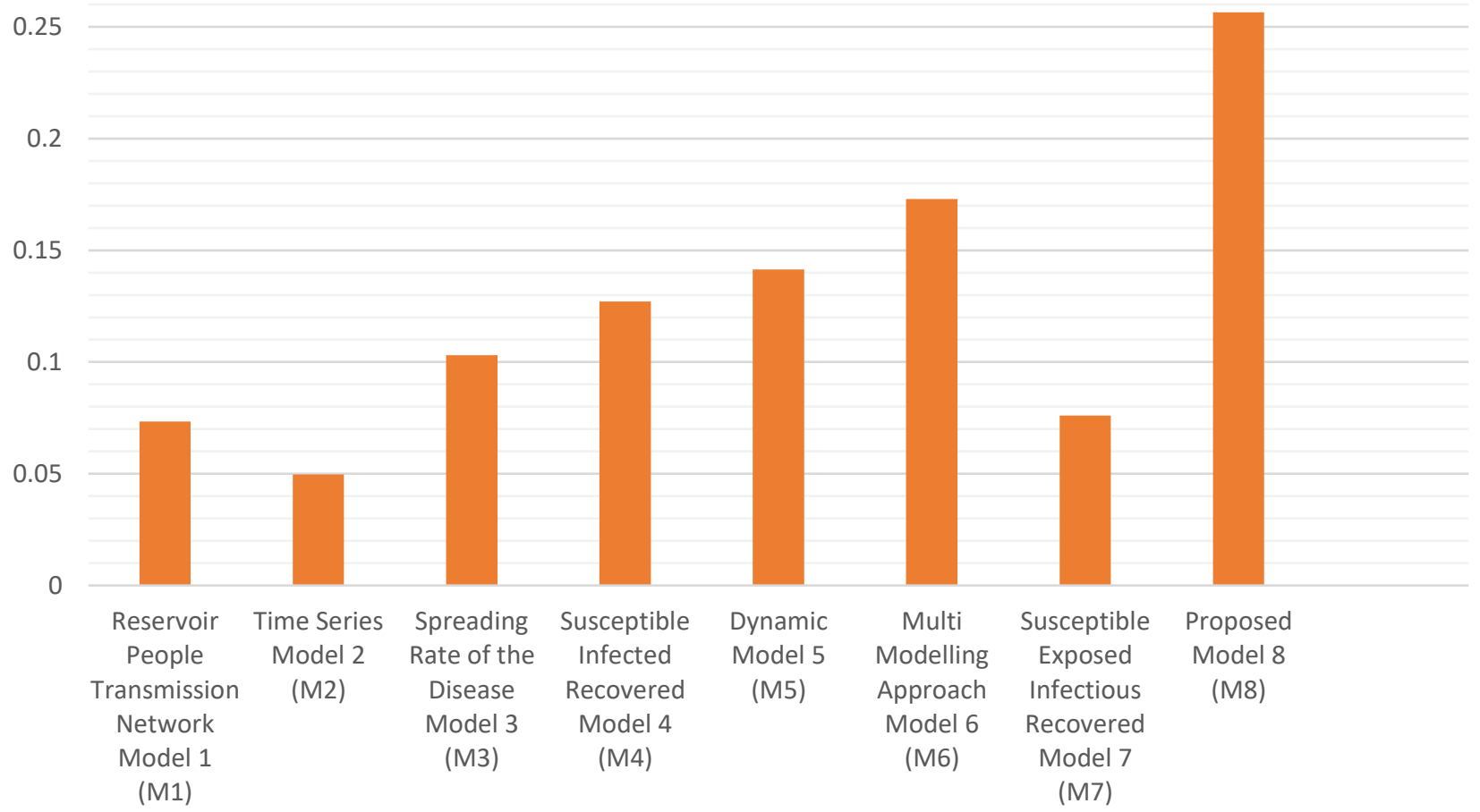

Figure. 4 Priorities of the models

\section{Author Contributions}

All authors contribute equally in this work.

\section{Acknowledgments}

This work was funded by Research and Development Grants Program for National Research Institutions and Centers (GRANTS), Target Research Program, Infections Diseases Research Grant Program, King Abdulaziz City for Science and Technology (KACST), Kingdom of Saudi Arabia, grant number (5-20-01-007-0028).

\section{References}

[1] COVID-19 Spread, available on https://who.sprinklr.com/, accessed on 2020.

[2] A. Rachah and D. F. M. Torres, "Mathematical Modelling, Simulation, and Optimal Control of the 2014 Ebola Outbreak in West Africa", Discrete Dynamics in Nature and Society, Vol. 2015 pp. 1-9, 2015.

[3] T.-M. Chen, J. Rui, Q.-P. Wang, Z.-Y. Zhao, J.A. Cui, and L. Yin, "A mathematical model for simulating the phase-based transmissibility of a novel coronavirus", Infectious Diseases of Poverty, Vol. 9, No. 1, pp. 1-8, 2020.
[4] Y. Li, B. Wang, R. Peng, C. Zhou, Y. Zhan, Z. Liu, X. Jiang, and B. Zhao, "Mathematical Modeling and Epidemic Prediction of COVID19 and Its Significance to Epidemic Prevention and Control Measures", Ann Infect Dis Epidemiol, Vol. 5, No. 1, pp.1-9, 2020.

[5] A. Kucharski, T. W. Russell, C. Diamond, Y. Liu, J. Edmunds, S. Funk, and R. M Eggo, "Early dynamics of transmission and control of COVID-19: a mathematical modelling study", The Lancet Infectious Diseases, Vol. 20, pp. 553-558, 2020.

[6] S. L. Chang, N. Harding, C. Zachreson, O. M. Cliff, and M. Prokopenko, "Modelling transmission and control of the COVID-19 pandemic in Australia", arXiv preprint arXiv: 2003. 10218

[7] M. Erraguntla, J. Zapletal, and M. Lawley, "Framework for Infectious Disease Analysis: A comprehensive and integrative multi-modeling approach to disease prediction and management", Health Informatics Journal, Vol. 25, No. 4, pp. 1170-1187, 2017.

[8] S. Marino, H.P. Gideon, C. Gong, S. Mankad, J. T. McCrone, P. L. Lin, and D. L. Kirschner, "Computational and Empirical Studies Predict Mycobacterium tuberculosis -Specific T Cells as a Biomarker for Infection Outcome", PLOS 
Computational Biology, Vol. 12, No. 4, pp. 2016.

[9] I. A. Gagnon, M. Habib, F. A. Ayoubi, G. Sutherland, A. Dobrescu, G. Villa, and K. AlHabib, "Modelling the burden of cardiovascular disease in Saudi Arabia and the impact of reducing modifiable risk factors", Journal of the Saudi Heart Association, Vol. 30, No. 4, pp. 204-253, 2018.

[10] S. Alshammari, and A. Mikler, "Data-Driven Computational Model to Assess the Risk of Epidemics in Global Mass Gatherings", Online Journal of Public Health Informatics, Vol. 10, No.1, pp. 1-2, 2018.

[11] M. Qasim, W. Ahmad, M. Yoshida, M. Gould, and M. Yasir, "Analysis of the Worldwide Corona Virus (COVID-19) Pandemic Trend; A Modelling Study to Predict Its Spread", Centre for Bioengineering and Nanomedicine (Dunedin), pp.1-16, 2020.

[12] F.-J. Schmitt, "A simplified model for expected development of the SARS-CoV-2 (Corona) spread in Germany and US after social distancing", arXiv: 2003. 10891 (2020).

[13] C. Hou, J. Chen, Y. Zhou, L. Hua, J. Yuan, S. He, Y. Guo, S. Zhang, Q. Jia, C. Zhao, J. Zhang, G. $\mathrm{Xu}$, and E. Jia, "The effectiveness of the quarantine of Wuhan city against the Corona Virus Disease 2019 (COVID-19): well-mixed SEIR model analysis", Journal of Medical Virolology, Vol. 92, No. 7, pp. 1-8, 2020.

[14] Z. Cakir and H.B. Savas, "A Mathematical Modelling Approach in the Spread of the Novel 2019 Coronavirus SARS-CoV-2 (COVID-19) Pandemic". Electron J. Gen. Med, Vol. 17, No. 4, pp. 1-3, 2020.

[15] COVID-19 Coronavirus Pandemic, https://www.worldometers.info/coronavirus/? Accessed 2020.

[16] COVID-19: Saudi Arabia expects 200,000 cases if measures not followed, https://gulfnews.com/world/gulf/saudi/covid19-saudi-arabia-expects-200000-cases-ifmeasures-not-followed-1.1586263454490. 2020.

[17] A. Agrawal, M. Zarour, M. Alenezi, R. Kumar, and RA. Khan, "Security durability assessment throughfuzzy analytic hierarchy process", PeerJComput. Sci., Vol. 5, pp. 1-41, 2019.

[18] Algarni, M. Ahmad, A. Attaallah, A. Agrawal, R. Kumar, and R. A. Khan, "A Fuzzy MultiObjective Covering based Security Quantification Model for Mitigating Risk of Web based Medical Image Processing System”, International Journal of Advanced Computer
Science and Applications. Vol. 11, No. 1, pp. 481-489, 2020.

[19] N. Zheng, S. Du, J. Wang, H. Zhang, W. Cui, Z. Kang, T. Yang, B. Lou, Y. Chi, H. Long, and M. Ma, "Predicting covid-19 in china using hybrid AI model", IEEE Transactions on Cybernetics, Vol. 50, No. 7, pp. 2891-2905, 2020.

[20] K. Sahu and R. K. Srivastava, "Soft Computing Approach for Prediction of Software Reliability”, ICIC Express Letters, Vol. 12, No. 12, pp. 1213-1222, 2018.

[21] J. P. Cohen, P. Morrison, L. Dao, K. Roth, T. Q. Duong, and M. Ghassemi, "COVID-19 image data collection: Prospective predictions are the future", arXiv preprint arXiv: 2006. 11988 (2020).

[22] R. Kumar, M. Zaroor, M. Alenezi, A. Agrawal, and R. A. Khan, "Measuring Security Durability of Software through Fuzzy-Based DecisionMaking Process", International Journal of Computational Intelligence Systems, Vol. 12, No. 2, pp. 627-642, 2019.

[23] K. Sahu and R. K. Srivastava, "Revisiting Software Reliability", Data Management, Analytics and Innovation. Springer, Vol. 254, pp. 221-235, 2019.

[24] R. Kumar, A. Baz, H. Alhakami, W. Alhakami, M. Baz, A. Agrawal, and R. A. Khan, "A Hybrid Model of Hesitant Fuzzy Decision-Making Analysis for Estimating Usable-Security of Software", IEEE Access, Vol. 8, No. 4, pp. 72694-72712, 2020.

[25] A. Agrawal, A. H. Seh, A. Baz, H. Alhakami, W. Alhakami, M. Baz, R. Kumar, R. A. Khan, "Software Security Estimation Using the Hybrid Fuzzy ANP-TOPSIS Approach: Design Tactics Perspective", Symmetry, Vol. 12, No.4, pp. 1-21, 2020.

[26] R. Kumar., A. K. Pandey, A. Baz, H. Alhakami, W. Alhakami, M. Baz, A. Agrawal, and R. A. Khan, "Fuzzy-Based Symmetrical MultiCriteria Decision- Making Procedure for Evaluating the Impact of Harmful Factors of Healthcare Information Security", Symmetry, Vol. 12, No. 664, pp. 1-23, 2020.

[27] R. Kumar, S. A. Khan, and R. A. Khan, "Analytical Network Process for Software Security: A Design Perspective", CSI Transactions, Vol. 4, No. 2, pp. 255-258, 2016.

[28] M. M. Sajadi, P. Habibzadeh, A. Vintzileos, S. Shokouhi, F.-W. Miralle, and A. Amoroso, "Temperature and latitude analysis to predict potential spread and seasonality for COVID-19", Jama Netw Open, Vol. 3, No. 6, p. 18, 2020. 
[29] R. Kumar, A. I. Khan, Y. B. Abushark, M. M. Alam, A. Agrawal, and R. A. Khan, "An Integrated Approach of Fuzzy Logic, AHP and TOPSIS for Estimating Usable-Security of Web Applications", IEEE Access, Vol. 8, pp. 5094450957, 2020.

[30] K. Sahu and R. Shree, "Stability: Abstract Roadmap of Software Security", American International Journal of Research in Science, Technology, Engineering and Mathematics, Vol.15, pp. 183-186, 2015.

[31] R. Kumar, A. I. Khan, Y. B. Abushark, M. M. Alam, A. Agrawal, and R. A. Khan, "A Knowledge Based Integrated System of Hesitant Fuzzy Set, AHP and TOPSIS for Evaluating Security-Durability of Web Applications", IEEE Access, Vol. 8, pp. 48870-48885, 2020.

[32] K. Sahu, R. Shree, and R. Kumar, "Risk Management Perspective in SDLC", International Journal of Advanced Research in Computer Science and Software Engineering, Vol. 4, No. 3, pp. 1247-1251, 2014.

[33] A. H. Seh, M. Zarour, M. Alenezi, A. K. Sarkar, A. Agrawal, R. Kumar, and R. A. Khan, R. A, "Healthcare Data Breaches: Insights and Implications, Healthcare", Vol. 8, No. 133, pp. 1-18, 2020.

[34] J. Kaur, A. I. Khan, Y. B. Abushark, M. M. Alam, S. A. Khan, A. Agrawal, R. Kumar, and R. A. Khan, "Security Risk Assessment of Healthcare Web Application through Adaptive Neuro-Fuzzy Inference System: A Design Perspective, Risk Management and Healthcare Policy", Dove Press, Vol. 13, pp. 355-371. 2020.

[35] R. Kumar, A. Agrawal, and R. A. Khan, "A wakeup Call to Data Integrity Invulnerability, Computer Fraud and Security", Elsevier. Available at Thomson Reuters, Vol. 2020, Issue 4, pp. 14-19, 2020.

[36] K. Sahu and R. K. Srivastava, "Needs and Importance of Reliability Prediction: An Industrial Perspective", Information Sciences Letters, Vol.9, No.1, pp. 33-37, 2020.

[37] L. Wynants, B. C. Van, M. M. Bonten, G. S. Collins, T. P. Debray, M. De Vos, M. C. Haller, G. Heinze, K.G. Moons, R. D. Riley, and E. Schuit, "Prediction models for diagnosis and prognosis of covid-19 infection: systematic review and critical appraisal", British Medical Journal (BMJ), Vol. 369, m. 1328, 2020.

[38] M. Mandal, S. Jana, S. K. Nandi, A. Khatua, S. Adak, and T. K. Kar, "A model based study on the dynamics of COVID-19: Prediction and control", Chaos, Solitons and Fractals, Vol. 136, pp. 1-12, 2020.
[39] M. A. Mohammed, "Benchmarking Methodology for Selection of Optimal COVID19 Diagnostic Model Based on Entropy and TOPSIS Methods", IEEE Access, Vol. 8, pp. 99115-99131, 2020, doi: 10.1109/2020.2995597. 